Revista Tecné, Episteme y Didaxis: TED. Año 2014, Número Extraordinario. ISSN Impreso: 0121-3814, ISSN web: 2323-0126

Memorias, Sexto Congreso Internacional sobre Formación de Profesores de Ciencias. 08 al 10 de octubre de 2014, Bogotá

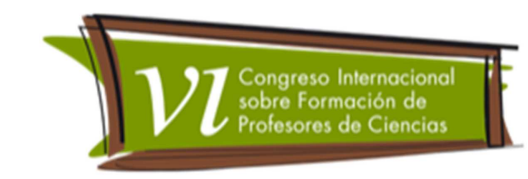

\title{
Aportes didácticos a la enseñanza de la genética
}

Martínez, Andrea' , Garzón, Lida², Aristizábal Andrea ${ }^{3}$

Categoría 1. Experiencias desde el aula

\section{Resumen}

En esta ponencia se describe una experiencia de aula con la temática de genética, como contenido curricular en el programa de ciencias experimentales para la educación básica. La propuesta se fundamentó en el modelo de resolución de problemas con la posibilidad de aproximar a los estudiantes a los procesos de alfabetización científica y en particular al desarrollo de pensamiento crítico y a la toma de decisiones responsables con sentido ético. La experiencia permitió promover en los educandos cambios enmarcados en lo conceptual de la genética y elementos relacionados, así como desde lo procedimental y actitudinal, que de esta temática puede derivarse. De igual manera las actividades propuestas estuvieron en consonancia con los propósitos nacionales de la formación en ciencias para nuevas generaciones.

\section{Palabras claves}

Clonación, ADN, aprendizaje, aprendizaje colaborativo y cooperativo, resolución de problemas.

\section{Introducción}

Los procesos de formación en ciencias desde las primeras edades, han de contribuir a promover en los educandos nuevas miradas acerca de la ciencia, su actividad, sus protagonistas y los efectos en la sociedad desde diferentes campos. Es por ello, que se requiere renovar la enseñanza de las ciencias y consecuencia las formas de aprender. Estos fundamentos de partida, se mencionan dado que lo que se evidencia en el aula, es que muchos de los estudiantes asisten al colegio pero no se identifican con lo que hacen; una de las causas es la desconexión de los contenidos con las realidades y problemáticas que viven los estudiantes (Solbes \& Vilches, 1997). En este ir y venir la formación en ciencias pasa inadvertida y no logra cumplir con su función primordial

\footnotetext{
IUniversidad Distrital Francisco José de Caldas. andrea.martinez1435@gmail.com 2Universidad Distrital Francisco José de Caldas. mariasinsal@hotmail.com 3Universidad Distrital Francisco José de Caldas. andrea_aristizabal@hotmail.com
} 
Revista Tecné, Episteme y Didaxis: TED. Año 2014, Número Extraordinario. ISSN Impreso: 0121-3814, ISSN web: 2323-0126

Memorias, Sexto Congreso Internacional sobre Formación de Profesores de Ciencias. 08 al 10 de octubre de 2014, Bogotá

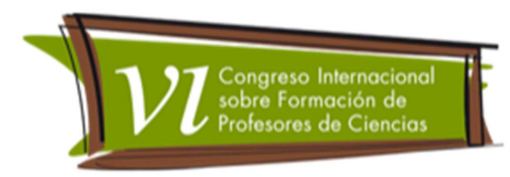

de alfabetizar científicamente, sino que se convierte en algo desmotivador, poco comprensible y escasamente aplicable a las realidades de los educandos. Otro factor determinante en esta dificultad es la forma en cómo se ha transformado la sociedad y la manera en cómo hoy los estudiantes perciben la cultura y la educación. Así mismo, es crucial el ambiente en el que se desarrollan los niños, el cual está íntimamente relacionado con el concepto de familia. Sin embargo, la globalización ha impulsado la formación de prototipos diferentes, en los cuales, es poco válido hablar de padres e hijos, pues existe una deformación del núcleo familiar, el cual omite la formación en valores y principios sociales, y pone a los actores del proceso de enseñanza y aprendizaje como los principales responsables de la formación del ciudadano. En otras palabras, la socialización primaria que debería estar a cargo de la familia está quedando en manos de los educadores (Savater, 1997).

Los fundamentos anteriores sirvieron para diseñar una unidad didáctica encaminada al desarrollo de competencias de pensamiento científico alrededor de la problemática, de si los animales que se han extinguido pueden hacer parte nuevamente de los ecosistemas, es decir si se pueden clonar. El abordaje de la temática surge por la falta de alfabetización científica, y buscaba más allá de responder esta pregunta trabajar el tema referente a la molécula de ADN, viéndola como la única que hace posible que la clonación pueda llevarse a cabo. Todo lo anterior, ligado a la parte axiológica como fundamento para una formación integral de los educandos.

Por todo lo anterior, se recurrió al modelo de Resolución de Problemas, que desde una misión en que el educando se vincula conceptual, procedimental y afectivamente, promueve en él, cambios por la responsabilidad individual y colectiva de lo que implica aceptar una misión, lo cual les permite involucrarse afectivamente con el conocimiento (Aristizabal, 2005).

\section{Desarrollo}

La implementación de las actividades que se plantean en esta unidad, trae consigo un aporte desde la perspectiva del aprendizaje significativo, enmarcado en la teoría del constructivismo, desarrollándola a partir de la concepción de resolución de problemas y apoyada en la vinculación afectiva de los estudiantes con el conocimiento desde su propia realidad. Es de vital importancia que el estudiante se vincule con lo que está aprendiendo, ya que esto puede constituirse en un aporte a la forma en cómo se movilizan los saberes en los estudiantes y otorgarle valor y sentido a la actividad científica, para que de esta manera potencien el pensamiento crítico requerido en la sociedad.

Temática 1. Enfoque CTS: Alfabetización científica y Cuestiones socio científicas 
Revista Tecné, Episteme y Didaxis: TED. Año 2014, Número Extraordinario. ISSN Impreso: 0121-3814, ISSN web: 2323-0126

Memorias, Sexto Congreso Internacional sobre Formación de Profesores de Ciencias. 08 al 10 de octubre de 2014, Bogotá

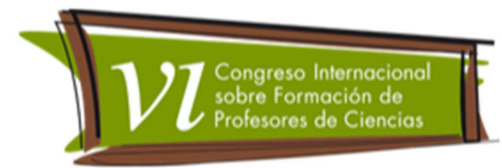

Al desarrollar esta unidad fue posible introducir actitudes propias de un aprendizaje colaborativo y cooperativo entre el docente, estudiantes y entre ellos mismos. Esto ayudo para que algunos estudiantes se aproximaran a preguntar y desglosar los conceptos desde la forma en cómo su compañero podría entenderlo y comunicarlo.

El planteamiento de las actividades, las competencias y las preguntas orientadoras con las cuales se ejecutó la unidad se encuentran descritas en la siguiente matriz (Tabla 1).

Tabla 1. Matriz de actividades a desarrollar en la unidad didáctica de clonación.

\begin{tabular}{|c|c|c|c|}
\hline Actividad & Competencias & Material de trabajo & Preguntas orientadoras \\
\hline $\begin{array}{l}\text { Actividad Rompe hielo " } \\
\text { Encuentra diferencias" }\end{array}$ & $\begin{array}{l}\text { Analizar las diferencias entre } \\
\text { los diagramas, haciendo un } \\
\text { acercamiento al concepto } \\
\text { de clon. }\end{array}$ & Icónico & $\begin{array}{lr}\text { ¿Por qué } & \text { somos } \\
\text { semejantes } & \text { pero } \\
\text { diferentes? } & \end{array}$ \\
\hline $\begin{array}{l}\text { Debate Artículo de } \\
\text { periódico el TIEMPO, } \\
\text { llamado "El dilema } \\
\text { científico de clonar las } \\
\text { especies } \\
\text { Podríamos ver Mamuts o } \\
\text { tigres dientes de sable } \\
\text { en algunos lugares del } \\
\text { planeta. }\end{array}$ & $\begin{array}{l}\text { Reconozco la importancia } \\
\text { del modelo de la doble } \\
\text { hélice para la explicación } \\
\text { del almacenamiento y } \\
\text { transmisión del material } \\
\text { hereditario. (conceptual) }\end{array}$ & Escrito & $\begin{array}{l}\text { ¿Qué entiendes por } \\
\text { clonación? } \\
\text { ¿Por qué crees que es } \\
\text { posible clonar animales } \\
\text { que ya se encuentran } \\
\text { extintos? }\end{array}$ \\
\hline $\begin{array}{l}\text { Proyección de video } \\
\text { (Rosalind Franklin) } \\
\text { Modelo analógico de } \\
\text { transcripción. } \\
\text { Explicación Fenotipos- } \\
\text { Genotipos }\end{array}$ & & $\begin{array}{l}\text { Audiovisual } \\
\text { Modelo analógico } \\
\text { (rompecabezas) } \\
\text { Uso de tablero y } \\
\text { material icónico. }\end{array}$ & $\begin{array}{l}\text { ¿Por qué me parezco a mi } \\
\text { papá y a mi mamá y no a } \\
\text { mi perro? }\end{array}$ \\
\hline $\begin{array}{l}\text { Explicación clara y } \\
\text { retroalimentación por } \\
\text { parte de las profesoras. }\end{array}$ & $\begin{array}{l}\text { Establezco relaciones entre } \\
\text { los genes, las proteínas y las } \\
\text { funciones celulares. } \\
\text { (explicación clara y } \\
\text { retroalimentación) } \\
\text { (conceptual) }\end{array}$ & $\begin{array}{l}\text { Uso de tablero y } \\
\text { material icónico. }\end{array}$ & $\begin{array}{l}\text { ¿Por qué hay personas de } \\
\text { diferentes razas? } \\
\text { ¿Químicamente en que } \\
\text { diferimos? }\end{array}$ \\
\hline $\begin{array}{l}\text { Hibridación en } \\
\text { productos como el arroz } \\
\text { y el café (Por grupos) }\end{array}$ & $\begin{array}{l}\text { Establezco la importancia } \\
\text { de mantener la } \\
\text { biodiversidad para estimular } \\
\text { el desarrollo del país. } \\
\text { (actitudinal) }\end{array}$ & Icónico & $\begin{array}{l}\text { ¿Consumimos } \\
\text { transgénicos? } \\
\text { ¿Solo existe clonación } \\
\text { animal? }\end{array}$ \\
\hline $\begin{array}{l}\text { Historieta " El asesino de } \\
\text { la calle Elm" }\end{array}$ & $\begin{array}{l}\text { Idéntico la utilidad del ADN } \\
\text { como herramienta de } \\
\text { análisis genético (In vitro). } \\
\text { Argumento las ventajas y }\end{array}$ & Escrito & ¿Para qué sirve el ADN? \\
\hline
\end{tabular}


Revista Tecné, Episteme y Didaxis: TED. Año 2014, Número Extraordinario. ISSN Impreso: 0121-3814, ISSN web: 2323-0126

Memorias, Sexto Congreso Internacional sobre Formación de Profesores de Ciencias. 08 al 10 de octubre de 2014, Bogotá

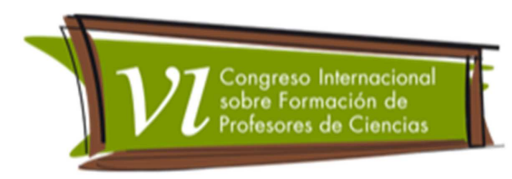

\begin{tabular}{|l|l|l|l|}
\hline & $\begin{array}{l}\text { desventajas de la } \\
\text { manipulación genética } \\
\text { (procedimental) }\end{array}$ & & \\
\hline
\end{tabular}

La matriz de evaluación en la tabla 2, está enfocada a evaluar competencias de pensamiento científico, tal como lo exige el MEN.

Tabla 2. Matriz de evaluación de las actividades realizadas.

\begin{tabular}{|c|c|}
\hline Competencias & Actividades \\
\hline $\begin{array}{l}\text { Reconozco la importancia del modelo de la } \\
\text { doble hélice para la explicación del } \\
\text { almacenamiento y transmisión del material } \\
\text { hereditario. (conceptual) }\end{array}$ & $\begin{array}{l}\text { Describe y explica la foto de Rosalind Franklin } \\
\text { identificando sus partes constituyentes y funciones. }\end{array}$ \\
\hline $\begin{array}{l}\text { Establezco relaciones entre los genes, las } \\
\text { proteínas y las funciones celulares. } \\
\text { (Explicación clara y retroalimentación) } \\
\text { (Conceptual) }\end{array}$ & $\begin{array}{l}\text { Escoja un órgano del cuerpo humano y a través de un } \\
\text { modelo (dibujo) representa los niveles de organización de } \\
\text { ese órgano desde la partes más grandes a las más } \\
\text { pequeñas. } \\
\text { ¿De este órgano se puede extraer información genética } \\
\text { para identificar y reconocer que persona era? }\end{array}$ \\
\hline $\begin{array}{l}\text { Identifico la utilidad del ADN como } \\
\text { herramienta de análisis genético (In vitro). }\end{array}$ & Resolución de problemas " el asesino de la calle Elm" \\
\hline $\begin{array}{l}\text { Establezco la importancia de mantener la } \\
\text { biodiversidad para estimular el desarrollo del } \\
\text { país. (actitudinal) } \\
\text { Argumento las ventajas y desventajas de la } \\
\text { manipulación genética (procedimental) }\end{array}$ & $\begin{array}{l}\text { Consulta de indagación sobre alimentos que en } \\
\text { Colombia se manipule genéticamente y elaborar un } \\
\text { poster en papel periódico y exponerlo a sus compañeros } \\
\text { en } 5 \text { min. } \\
\text { Características del poster: Imagen, la información de } \\
\text { manipulación genética y los productos mejorados. }\end{array}$ \\
\hline
\end{tabular}

\section{Resultados}

Con la aplicación de la unidad se logró evidenciar algunas concepciones alternativas que poseían los estudiantes respecto a la temática clonación, algunos de ellos planteaban que "Clonación es una molécula igual o parecida sobre una persona o animal"; o que "Clonación es doblar o resucitar un animal". Las actividades propuestas permitieron potenciar habilidades discursivas de acuerdo con las hipótesis que estaban contenidas en el artículo del periódico sobre clonar animales extintos; de 
Revista Tecné, Episteme y Didaxis: TED. Año 2014, Número Extraordinario. ISSN Impreso: 0121-3814, ISSN web: 2323-0126

Memorias, Sexto Congreso Internacional sobre Formación de Profesores de Ciencias. 08 al 10 de octubre de 2014, Bogotá

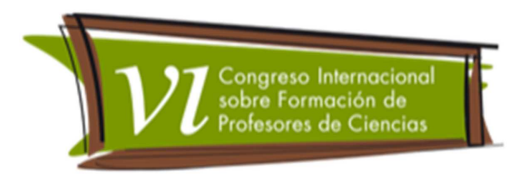

igual manera permitió fortalecer las actitudes críticas sobre lo que muestran los medios de comunicación.

Con el uso del modelo de resolución de problemas se logró fortalecer las competencias procedimental y conceptual planteadas en la Tabla 1 y desarrolladas a través de la actividad "El asesino de la calle Elm" (modificada de un ejercicio de pruebas pisa, 2013). Esto se evidencio a través de las respuestas obtenidas a dos preguntas cerradas elaboradas para la comprensión lectora de los estudiantes sobre la historieta; la pregunta uno estaba enfocada a identificar el concepto de ADN y la pregunta dos sobre las cuestiones científicas que ocupaban la investigación en ciencias. Se puede argumentar que para la pregunta uno, $68 \%$ de los estudiantes pudieron abstraer el concepto del ADN a partir de la explicación de fenómenos científicos en un contexto social y próximo a su realidad, teniendo en cuenta que esto los movió afectivamente, ya sea, haciendo una relación ciencia- ficción o de lo que podían abstraer con las tecnologías que se desarrollan en función de los conocimientos científicos que a su vez son más próximos al común denominador de la población, como es el caso de un perfil de ADN. En cuanto a la pregunta 2, también se puede argumentar que el $64 \%$ de los estudiantes identificó las tareas de la investigación científica y cuáles de estas cuestiones propuestas en las opciones de respuesta definitivamente no es posible y no hace parte de lo que se ocupa la ciencia y las tecnologías asociadas al desarrollo de la biología.

La actividad que consistía en diseñar un "mini poster", sirvió para que los alumnos pudieran plasmar sus pensamientos frente a un tema que suscita polémica como lo son los transgénicos. Esta aplicación de la genética proporcionó argumentos críticos sobre los alcances políticos, sociales y económicos que se mueven entorno a los organismos genéticamente modificados. Se pudo cultivar una nueva percepción de la ciencia, ya que ellos ampliaron su visión sobre la trayectoria de la ciencia y su impacto en la sociedad como un motor de desarrollo que implica cuestiones éticas y morales.

En la actividad de la proyección del video de Rosalind Franklin se trabajaron las diferentes posturas de los estudiantes respecto a las actitudes que tuvieron Watson y Crick respecto al descubrimiento de la molécula de ADN, este proceso se planteó en un debate en el cual algunos de ellos manifestaron actitudes de tipo afectivo en las que argumentaban estar a favor o en contra de dichas actitudes, así como el papel de la mujer en el campo científico. 
Revista Tecné, Episteme y Didaxis: TED. Año 2014, Número Extraordinario. ISSN Impreso: 0121-3814, ISSN web: 2323-0126

Memorias, Sexto Congreso Internacional sobre Formación de Profesores de Ciencias. 08 al 10 de octubre de 2014, Bogotá

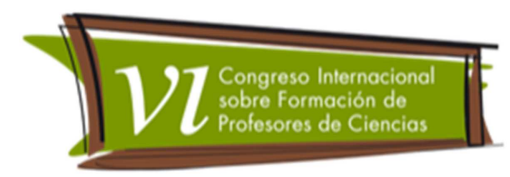

Entre otros aspectos el aprendizaje colaborativo y cooperativo, promueve desarrollos personales y sociales que fueron visualizados a través de las interacciones que se suscitaron entre los estudiantes, algunos dejaron ver un interés y otros entablaron una conversación con compañeros que al estar en el diario vivir no se relacionan tan directamente. Estas nuevas dinámicas promovieron preguntas en el aula, esta curiosidad es la que precisamente trata de cosechar la Universidad Distrital en los seminarios de didáctica de las ciencias. Este tipo de aprendizaje se tornó flexible con el docente, permitiéndole prestar más atención a los estudiantes que no se encontraban dentro del proceso de aprendizaje ayudándolos a descubrir una motivación para analizar lo que estaba a su alrededor.

Los aportes didácticos de esta unidad son evidentes en la apropiación de los conocimientos por parte de los alumnos, se observó que para muchos de ellos la actividad de encontrar las diferencias les resulto interesante, por tanto, esta estrategia permitió ver el juego como un ejercicio donde el conocimiento se disfrazó de creatividad y diversión.

\section{Conclusiones}

La vinculación entre el modelo de resolución de problemas desde misiones que vinculan cognitiva, procedimental y afectivamente a los educandos con el modelo de aprendizaje cooperativo y colaborativo, se constituyen en nuevas formas para la enseñanza y el aprendizaje de las ciencias. Por cuanto implica no solo dominar contenidos, sino tomar posturas críticas frente a lo construido y de someterlo a validación con los otros, lo que fortalece y da sentido a la actividad científica que se promueve desde el aula.

Las estrategias de enseñanza diseñadas generan opciones de innovación, representan un material amplio y diversificado que permite que la enseñanza se torne interesante, reconociendo que cada educando posee formas específicas de relacionarse con el conocimiento.

Mantener un constante acercamiento con las enormes cantidades de información, es una manera de entender nuestro mundo y su acelerado cambio, algunos de los medios por los cuales transitan todos estos datos son los periódicos, con esta herramienta no solo se puede explotar e incentivar la capacidad lectora, sino que también sirve de plataforma para explorar las noticias más interesantes acerca de lo que la ciencia y otros sectores de la sociedad hacen día a día.

Temática 1. Enfoque CTS: Alfabetización científica y Cuestiones socio científicas 
Revista Tecné, Episteme y Didaxis: TED. Año 2014, Número Extraordinario. ISSN Impreso: 0121-3814, ISSN web: 2323-0126

Memorias, Sexto Congreso Internacional sobre Formación de Profesores de Ciencias. 08 al 10 de octubre de 2014, Bogotá

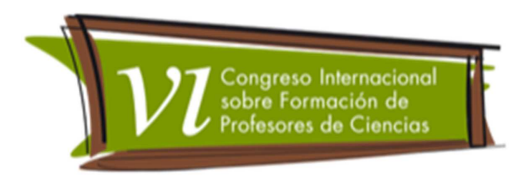

\section{Referencias Bibliográficas}

Aristizabal, A. (2005). Los conceptos de calor y temperatura desde la enseñanza de las competencias cognoscitivas y los estándares de competencia. (Tesis de maestría). Universidad Pedagógica Nacional, Bogotá-Colombia.

Savater, F. (1997). El eclipse de la familia. En El Valor de Educar. (pp 26-39). Editorial Ariel, S. A. Barcelona- España.

Solbes, J. \&Vilches, A. (1997): STS interactions and the teaching of physics and chemistry, Science Education, 81 (4), 377-386. Recuperado de: http://www.learningdomain.com/STS.Chem.Physics.pdf

Pisa (2013) Capturar al Asesino. Madrid- España. Recuperado de: http://recursostic.educacion.es/inee/pisa/ciencias/cienciaspisa/biologia/biologia _er/01_cienciasbio_capturar_al_asesino_er.pdf. 